\title{
Deeply reconsidering elective surgery: worldwide concerns regarding colorectal surgery in a COVID-19 pandemic and a Singapore perspective
}

\author{
Min Hoe $\underline{\text { Chew }}{ }^{1}$, MBBS, FRCSEd, Winson Jianhong $\underline{T a n}^{1}$, MBBS(Hons), FRCSEd, Chee Yung $\underline{N g}^{2}$, MBBS, FRCSEd,
} Kheng Hong $\mathrm{Ng}^{3}$, MBBS, FRCSEd

\section{INTRODUCTION}

The coronavirus disease 2019 (COVID-19) pandemic crisis in Singapore crossed a milestone on 1 April 2020 with 1,000 infections and four deaths. ${ }^{(1)}$ For the rest of the world, the surge of cases has been unprecedented. While the first 500,000 cases occurred in almost three and a half months, the next 500,000 patients were infected in less than two weeks, with the total number of infected individuals having just exceeded one million as of 3 April 2020. ${ }^{(2)}$ It is, however, important to acknowledge that reported cases may represent the tip of an iceberg, and true infection rates may be much higher. ${ }^{(3)}$ In this climate, surgical safety has emerged as a topic of immense interest.

Multiple guidelines from Europe and the United States have been issued between 18 March and 31 March 2020, (4-7) $^{(2 r a f t e d ~ i n ~}$ anticipation of worsening case numbers based on the experience in Italy and China. These guidelines largely advocate to cease most elective general surgeries and only perform emergency work. The aim is mainly to avoid the risks of viral transmission, as well as to conserve valuable personal protection equipment (PPE) resources. In addition, manpower is needed to augment healthcare workers at the front line. The recommendations are summarised in Table I. ${ }^{(4-7)}$

\section{WHAT WE UNDERSTAND SO FAR}

Colorectal surgery exists as a separate subspecialty in several countries, ${ }^{(8)}$ while the key concerns of COVID-19 specific to gastrointestinal surgeons mainly revolve around the dangers of viral transmission. Previous experiences with the severe acute respiratory syndrome coronavirus (SARS-CoV) and Middle East respiratory syndrome coronavirus (MERS-CoV) suggest similar concerns with COVID-19. Both SARS-CoV and MERS-CoV have clinical presentations of diarrhoea with evidence of faecal excretion. ${ }^{(9,10)}$ These viruses are also found to be viable in environmental conditions that facilitate faecal-oral transmission, with reports of SARS-CoV RNA found in the sewage water of hospitals that treated SARSCoV patients. ${ }^{(11)}$ COVID-19 transmission is largely similar and includes respiratory droplets, fomites, contact and the faecal-oral route. ${ }^{(12,13)}$ It was proposed that the mechanism of gastrointestinal tract infection in SARS-CoV patients is via the angiotensin-converting enzyme 2 (ACE2) cell receptor; initial reports of COVID-19 not only confirm ACE2 as a host receptor but also that the virus uses human ACE2 more efficiently, possibly suggesting higher infectivity. ${ }^{(14)}$ Like SARS-CoV and MERS-CoV, there is also evidence of prolonged presence of SARS-CoV-2 in the environment, which can facilitate faecaloral transmission from environmental contamination. ${ }^{(15)}$

While there has been no conclusive evidence of airborne transmission of COVID-19, past experience shows that SARS-CoV can be transmitted via aerosol-generating procedures (AGPs). ${ }^{(16)}$ Intubation was the independent risk factor for super-spreading nosocomial outbreaks affecting many healthcare workers in Hong Kong and Guangzhou, China. ${ }^{(17)}$ Recent experimental evidence suggests that SARS-CoV-2 has aerosol stability of up to three hours. ${ }^{(18)}$

Pertinent to colorectal surgeons is the high volume of diagnostic and screening endoscopy procedures performed daily. Laparoscopic surgery is also commonly performed. There is currently scant evidence regarding the relative risks of virus transmission of minimally invasive surgery as compared to open surgery. Data does indicate that laparoscopy can lead to aerosolisation of blood-borne viruses, although the applicability to SARS-CoV-2 remains unknown. ${ }^{(19,20)}$ In laparoscopic colorectal surgery, as compared to the commonly performed laparoscopic appendectomies and cholecystectomies, there is bowel handling during retraction and dissection, with some risk of inadvertent bowel perforations. While bowel preparation is often done preoperatively, it is not used by many surgeons in this era of enhanced recovery, and hence there may be risks of faecal spillage into the pneumoperitoneum. Furthermore, there are patients who are on long-term steroids for conditions such as inflammatory bowel disease and those on immunosuppressant drugs for other autoimmune conditions. It is also not uncommon for the Asian population to consume herbal remedies and traditional medicine for health supplementation, some of which contain steroids. While all these conditions may provide an increased risk of bacterial translocation, there is no evidence to suggest that there is a concurrent higher viral load in the pneumoperitoneum during laparoscopic surgery. ${ }^{(21)}$ Despite the lack of definitive conclusions in the literature, published guidelines have advised caution in view of the theoretical risks.

${ }^{1}$ Department of General Surgery, Colorectal Service, Sengkang General Hospital, ${ }^{2}$ One Surgical Clinic \& Surgery, ${ }^{3} \mathrm{KH}$ Ng Colorectal \& Minimally Invasive Surgery, Singapore Correspondence: Adj A/Prof Chew Min Hoe, Head and Senior Consultant, Department of General Surgery, Colorectal Service, Sengkang General Hospital, 110 Sengkang East Way, Singapore 544886. chew.min.hoe@singhealth.com.sg 
Table I. Recommendations of various professional societies on surgical procedures during the COVID-19 pandemic.

\begin{tabular}{|lll|}
\hline Professional society (date) & Endoscopy & Surgery \\
\hline $\begin{array}{l}\text { SAGES and EAES } \\
\text { (29 March 2020) }\end{array}$ & All elective cases to be postponed & $\begin{array}{l}\text { All elective cases to be postponed. } \\
\text { Surgical care limited to those whose } \\
\text { needs are imminently life-threatening }\end{array}$ \\
\hline $\begin{array}{l}\text { Gastroenterology professional society guidance } \\
\text { from ASGE, AGA, ACG, AASLD (31 March 2020) }\end{array}$ & $\begin{array}{l}\text { All elective procedures to be delayed. To } \\
\text { proceed with evaluation for patients with } \\
\text { time-sensitive diagnosis }\end{array}$ & NA \\
\hline $\begin{array}{l}\text { European Society of Gastrointestinal Endoscopy } \\
\text { (18 March 2020) }\end{array}$ & $\begin{array}{l}\text { Strongly consider postponing elective, non- } \\
\text { urgent procedures }\end{array}$ & NA \\
\hline $\begin{array}{l}\text { Intercollegiate General Surgery Guidance } \\
\text { (27 March 2020) }\end{array}$ & $\begin{array}{l}\text { Only emergency procedures to be } \\
\text { performed. No diagnostic work to be done }\end{array}$ & $\begin{array}{l}\text { Largely confined to emergency surgery. } \\
\text { Stoma formation to be considered } \\
\text { rather than anastomosis }\end{array}$ \\
\hline American College of Surgeons (24 March 2020) & NA & \begin{tabular}{l} 
Tiered approach for cancer cases \\
\hline
\end{tabular}
\end{tabular}

AASLD: American Association for the Study of Liver Diseases; ACG: American College of Gastroenterology; AGA: American Gastroenterological Association; ASGE: American Society for Gastrointestinal Endoscopy; COVID-19: coronavirus disease 2019; EAES: European Association for Endoscopic Surgery; NA: not applicable; SAGES: Society of American Gastrointestinal and Endoscopic Surgeons

\section{CURRENT SITUATION AND CRISIS PLANNING CONSIDERATIONS FOR COLORECTAL SURGERY IN SINGAPORE}

For colorectal surgery in the current COVID-19 situation, there is considerable overlap with the principles for general surgery laparoscopy and endoscopy procedures. We have advised the following key measures: (a) mandatory pre-surgery risk stratification with deliberate postponements; (b) AGP procedures being performed with adequate PPE and eye protection; and (c) judicious and controlled use of PPE. ${ }^{(22)}$ These measures are summarised in Box 1. For colorectal surgery specifically, transanal procedures may have to be approached with the same caution as an AGP, especially in transanal minimally invasive surgery and transanal total mesorectal excision procedures.

There are, however, warning signs that the disease outbreak is not contained or fully understood. Worryingly, reports of presymptomatic transmission have been documented in China and lately confirmed in Singapore. ${ }^{(23-25)}$ This creates a whole new dimension in risk stratification of patients and suggests that clinical history may be insufficient. While our local data indicates that pre-symptomatic transmission can occur in $6.4 \%$ of all patients, it has been reported to occur at a rate of $12.6 \%$. $^{(26)}$ As case numbers continue to rise, the utility of valuable intensive care unit beds with ventilators as well as PPE consumption needs to be better rationalised. There has to be a reduction in non-essential surgeries. With these considerations in mind, we herein propose five principles of management of colorectal surgery during the crisis:

(a) Consider performing two COVID-19 swabs at least 3-5 days apart preoperatively for all elective colorectal surgery. This addresses the higher theoretical risk of faecal-oral transmission and avoids missing pre-symptomatic patients.

(b) Cancer surgery can continue, but consider performing open surgery to reduce risks.

(c) Consider bowel preparation for all elective colorectal surgeries.

(d) Cases to be deferred include perianal procedures, pelvic floor procedures, polyposis and inflammatory bowel disease

\section{Box 1. Proposed measures for procedures during COVID-19} pandemic:

Pre-procedure risk stratification of patients undergoing endoscopy or surgery

- Procedure to be rescheduled for high-risk patients with no clinical urgency

- Cases deemed clinically urgent to proceed with appropriate personal protective equipment (PPE) protection

- History of fever or respiratory symptoms

- Family members or close contacts with the above symptoms

- Any contact with a suspicious or confirmed case of COVID-19

- Any recent travel history, especially to high-risk areas

PPE for all endoscopy procedures and laparoscopic cases

- Face shields/eye goggles

- N95 respirator masks

- Gloves

- Waterproof gown

PPE for proctology and open colorectal cases

- Face shields/eye goggles

- Surgical mask

- Gloves

- Waterproof gown

PPE for high-risk cases (based on pre-procedure risk stratification) or COVID-19-positive patients

- Face shields/eye goggles

- Powered air-purifying respirator

- Gloves

- Waterproof gown

prophylaxis surgeries. Stoma closures can be deferred if no complications arise from the stoma.

(e) Consider alternative/non-operative treatment approaches (assuming resources permit), especially for benign colorectal disease (e.g. percutaneous drain for early stage complicated diverticular disease).

There must be stringent considerations for colorectal surgery in a pandemic crisis due to heightened theoretical risks of viral transmission in both diagnostic and therapeutic procedures. Nonetheless, due to the high volume of patients, the specialty cannot afford to stop work abruptly. Social distancing 
considerations for our patients and patient support groups, as well as protection for our stoma therapists, have to be planned. This ensures optimal care in this difficult period that may potentially be protracted.

\section{REFERENCES}

1. Ministry of Health, Singapore. Five more cases discharged; 74 new cases of COVID-19 confirmed. Available at: https://www.moh.gov.sg/news-highlights/ details/five-more-cases-discharged-74-new-cases-of-covid-19-infectionconfirmed. Accessed April 3, 2020.

2. Coronavirus COVID-19 global cases. In: John Hopkins University \& Medicine Coronavirus Resource Centre. Available at: https://coronavirus.jhu.edu/map. html. Accessed April 3, 2020.

3. Li R, Pei S, Chen B, et al. Substantial undocumented infection facilitates the rapid dissemination of novel coronavirus (SARS-CoV2). Science 2020; 368:489-93.

4. European Society of Gastrointestinal Endoscopy. ESGE and ESGENA Position Statement on gastrointestinal endoscopy and the COVID-19 pandemic. Available at: https://www.esge.com/esge-and-esgena-position-statement-ongastrointestinal-endocscopy-and-the-covid-19-pandemic. Accessed April 3, 2020.

5. Society of American Gastrointestinal and Endoscopic Surgeons. SAGES and EAES recommendations regarding surgical response to COVID-19 crisis. Available at: https://www.sages.org/recommendations-surgical-response-covid-19. Accessed April 3, 2020

6. American College of Surgeons. COVID-19 guidelines for triage of colorectal cancer patients. Available at: https://www.facs.org/covid-19/clinical-guidance/ elective-case/colorectal-cancer. Accessed April 3, 2020.

7. The Royal College of Surgeons of Ediburgh. Intercollegiate general surgery guidance on COVID-19 update. Available at: https://www.rcsed.ac.uk/newspublic-affairs/news/2020/march/intercollegiate-general-surgery-guidance-oncovid-19-update. Accessed April 3, 2020.

8. Goligher J. Colorectal surgery as a specialty. Dis Colon Rectum 1997; 40:733-5

9. WHO issues consensus document on the epidemiology of SARS. Wkly Epidemiol Rec 2003; 78:373-5.

10. Assiri A, Al-Tawfiq JA, Al-Rabeeah AA, et al. Epidemiological, demographic, and clinical characteristics of 47 cases of Middle East respiratory syndrome coronavirus disease from Saudi Arabia: a descriptive study. Lancet Infect Dis 2013; 13:752-61.

11. Wang XW, Li J, Guo T, et al. Concentration and detection of SARS coronavirus in sewage from Xiao Tang Shan Hospital and the 309th Hospital of the Chinese People's Liberation Army. Water Sci Technol 2005; 52:213-21.

12. Wu Z, McGoogan JM. Characteristics of and important lessons from the coronavirus disease 2019 (COVID-19) outbreak in China: summary of a report of 72314 cases from the Chinese Center for Disease Control and Prevention. JAMA 2020; 323:1239-42.

13. Yeo C, Kaushal S, Yeo D. Enteric involvement of coronaviruses: is faecal-oral transmission of SARS-CoV-2 possible? Lancet Gastroenterol Hepatol 2020; 5:335-7.

14. Wan Y, Shang J, Graham R, Baric RS, Li F. Receptor recognition by the novel coronavirus from Wuhan: an analysis based on decade-long structural studies of SARS coronavirus. J Virol 2020; 94. pii: e00127-20.

15. Ong SWX, Tan YK, Chia PY, et al. Air, surface environmental, and personal protective equipment contamination by severe acute respiratory syndrome coronavirus 2 (SARS-CoV-2) from a symptomatic patient. JAMA 2020; 323:1610-2.

16. Scales DC, Green K, Chan AK, et al. Illness in intensive care staff after brief exposure to severe acute respiratory syndrome. Emerg Infect Dis 2003; 9:120510.

17. Guan WJ, Ni ZY, Hu Y, et al. Clinical characteristics of coronavirus disease 2019 in China. N Engl J Med 2020; 382:1708-20.

18. van Doremalen N, Bushmaker T, Morris DH, et al. Aerosol and surface stability of SARS-CoV-2 as compared with SARS-CoV-1. N Engl I Med 2020; 382:1564-7.

19. Alp E, Bijl D, Bleichrodt RP, Hansson B, Voss A. Surgical smoke and infection control. J Hosp Infect 2006; 62:1-5.

20. Choi SH, Kwon TG, Chung SK, Kim TH. Surgical smoke may be a biohazard to surgeons performing laparoscopic surgery. Surg Endosc 2014; 28:2374-80.

21. Haak BW, Wiersinga WJ. The role of the gut microbiota in sepsis. Lancet Gastroenterol Hepatol 2017; 2:135-43.

22. Chew MH, Koh FH, Ng KH. A call to arms: a perspective of safe general surgery in Singapore during the COVID-19 pandemic. Singapore Med J 2020; 61:378-80.

23. Qian G, Yang N, Ma AHY, et al. A COVID-19 transmission within a family cluster by presymptomatic infectors in China. Clin Infect Dis 2020; 71:861-2.

24. Tong ZD, Tang A, Li KF, et al. Potential presymptomatic transmission of SARSCoV-2, Zhejiang Province, China, 2020. Emerg Infect Dis 2020; 26:1052-4.

25. Wei WE, Li ZB, Chiew CJ, et al. Presymptomatic Transmission of SARS-CoV-2Singapore, January 23-March 16, 2020. MMWR Morb Mortal Wkly Rep 2020; 69:411-5.

26. Kimball A, Hatfield KM, Arons M, et al. Asymptomatic and presymptomatic SARS-CoV-2 infections in residents of a long-term care skilled nursing facility King County, Washington, March 2020. MMWR Morb Mortal Wkly Rep 2020; 69:377-81. 